\title{
Full penetration laser beam welding of thick duplex steel plates with electromagnetic weld pool support
}

Cite as: J. Laser Appl. 28, 022420 (2016); https://doi.org/10.2351/1.4944103

Submitted: 29 February 2016 . Accepted: 04 March 2016 . Published Online: 31 March 2016

Vjaceslav Avilov, André Fritzsche, Marcel Bachmann, Andrey Gumenyuk, and Michael Rethmeier
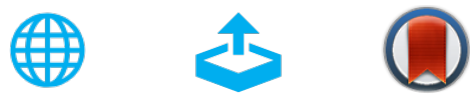

View Online

Export Citation

CrossMark

\section{ARTICLES YOU MAY BE INTERESTED IN}

Finite element modeling of an alternating current electromagnetic weld pool support in full penetration laser beam welding of thick duplex stainless steel plates

Journal of Laser Applications 28, 022404 (2016); https://doi.org/10.2351/1.4943906

Magnetic stirring during laser welding of aluminum

Journal of Laser Applications 18, 28 (2006); https://doi.org/10.2351/1.2164477

Welding of thick stainless steel plates up to $50 \mathrm{~mm}$ with high brightness lasers

Journal of Laser Applications 23, 022002 (2011); https://doi.org/10.2351/1.3567961

\section{Sellight Highlights of the best new research} in the physical sciences 


\title{
Full penetration laser beam welding of thick duplex steel plates with electromagnetic weld pool support
}

\author{
Vjaceslav Avilov and André Fritzsche \\ Institute of Machine Tools and Factory Management, Technical University Berlin, Pascalstraße 8-9, \\ 10587 Berlin, Germany \\ Marcel Bachmann and Andrey Gumenyuk \\ BAM Federal Institute for Materials Research and Testing, Unter den Eichen 87, Berlin 12205, Germany
}

\author{
Michael Rethmeier \\ Institute of Machine Tools and Factory Management, Technical University Berlin, Pascalstraße 8-9, \\ 10587 Berlin, Germany and BAM Federal Institute for Materials Research and Testing, Unter den Eichen 87, \\ Berlin 12205, Germany
}

(Received 29 February 2016; accepted for publication 4 March 2016; published 31 March 2016)

\begin{abstract}
Full penetration high power bead-on-plate laser beam welding tests of up to $20 \mathrm{~mm}$ thick 2205 duplex steel plates were performed in PA position. A contactless inductive electromagnetic (EM) weld pool support system was used to prevent gravity drop-out of the melt. Welding experiments with $15 \mathrm{~mm}$ thick plates were carried out using IPG fiber laser YLR 20000 and Yb:YAG thin disk laser TruDisk 16002. The laser power needed to achieve a full penetration was found to be 10.9 and $8.56 \mathrm{~kW}$ for welding velocity of 1.0 and $0.5 \mathrm{~m} \mathrm{~min}^{-1}$, respectively. Reference welds without weld pool support demonstrate excessive root sag. The optimal value of the alternating current (AC) power needed to completely compensate the sagging on the root side was found to be $\approx 1.6 \mathrm{~kW}$ for both values of the welding velocity. The same EM weld pool support system was used in welding tests with $20 \mathrm{~mm}$ thick plates. The laser beam power (TRUMPF Yb:YAG thin disk laser TruDisk 16002) needed to reach a full penetration for $0.5 \mathrm{~m} \mathrm{~min}^{-1}$ was found to be $13.9 \mathrm{~kW}$. Full penetration welding without EM weld pool support is not possible-the surface tension cannot stop the gravity drop-out of the melt. The AC power needed to completely compensate the gravity was found to be $2 \mathrm{~kW}$. (C) 2016 Laser Institute of America. [http://dx.doi.org/10.2351/1.4944103]
\end{abstract}

Key words: electromagnetic weld pool control, duplex stainless steel, laser beam welding, full penetration welding

\section{INTRODUCTION}

Modern high-power laser sources allow advanced thickplate welding applications and enable a stable single-pass welding process even for thick metal plates. The advantages of keyhole mode laser beam welding, such as high welding speed and low heat input, are well known. An especially high weld quality is achieved in single pass PA position full penetration keyhole laser beam welding. The laser beam forms a narrow weld pool with nearly parallel side walls. This results in very low buckling and bending of the workpiece, see, e.g., Ref. 1. However, for full penetration welding of thick metal parts, the surface tension cannot compensate the hydrostatic pressure in the melt. This can result in sagging of the root side of the weld or even a complete drop-out of the melt, when the workpiece thickness is above some threshold, see Fig. 1.

The hydrostatic pressure of liquid metal on the root side of the weld pool is

$$
p_{h}=\rho g_{o} h,
$$

where $\rho$ is the density of the melt, $g_{0}=9.81 \mathrm{~m} \mathrm{~s}^{-2}$ is the gravity acceleration, and $h$ is the plate thickness.

Gravity dropout takes place when the hydrostatic pressure exceeds that of the surface tension

$$
p_{\text {surf }}=\gamma / R
$$

where $\gamma$ is the surface tension coefficient and $R$ is the curvature radius. The Laplace pressure (2) reaches its maximum value at $\alpha=90^{\circ}$ and $R=w / 2$, where $\alpha$ is the contact angle, and $w$ is the width of the weld pool, see Fig. 2. The weld pool remains stable when the hydrostatic pressure does not exceed the maximum value of the Laplace pressure

$$
p_{h}<\frac{2 \gamma}{w}
$$

or

$$
h w<2 l_{\text {cap }}^{2}
$$

where $l_{\text {cap }}=\left[\gamma /\left(\rho g_{0}\right)\right]^{1 / 2}$ is the capillary length. Figure 2 shows also the stability threshold for liquid steel $(\rho=6.9$ $\times 10^{3} \mathrm{~kg} \mathrm{~m}^{-3}, \gamma=1.8 \mathrm{~N} \mathrm{~m}^{-1}$, and $l_{\text {cap }} \approx 5.3 \mathrm{~mm}$ ).

Welding tests with all high-power laser types (solid state fiber or thin disk, as well as $\mathrm{CO}_{2}$ beam sources) show that for up to approximately $16 \mathrm{~mm}$ thick steel, the welds can be formed in the flat position. ${ }^{2}$ Fusion zones normally exhibit depth-to-width ratios in the range of 10:1, resulting in very low energy input and minimum distortion as well as 


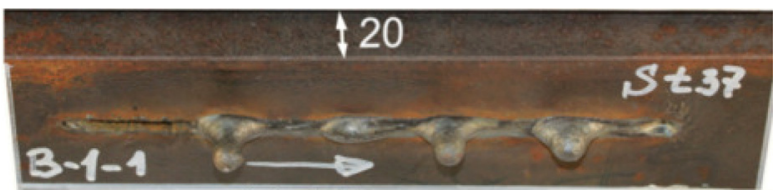

FIG. 1. Gravity drop-out of the melt in a full penetration welding of $20 \mathrm{~mm}$ thick S235JR steel plate using $13.9 \mathrm{~kW}$ laser power (YLR 20000 IPG) without weld pool support, the welding velocity was $0.5 \mathrm{~m} \mathrm{~min}^{-1}$.

relatively high welding speed. ${ }^{2}$ A backup bar can be used if it is necessary to weld thicker materials in the flat position. However, backup bars usually become fused to the weldment and are difficult to remove.

Increasing welding speed is one method of reducing the weld width and increasing the Laplace (surface) pressure supporting the weld pool. However, there are some reasons to renounce too narrow seams:

- To achieve the needed penetration depth, it is necessary to increase the laser beam power, too. For example, in single pass welding of $20 \mathrm{~mm}$ thick plates with welding velocity $1.8 \mathrm{~m} \mathrm{~min}^{-1}$ the weld pool remains stable, ${ }^{3}$ see Fig. 3. The weld width was $2.3 \mathrm{~mm}$ (root side) with a sagging $\sim 1.1 \mathrm{~mm}$. However, the needed laser beam power of $18 \mathrm{~kW}$ is too large for many industrial applications.

- High power laser joining of thick metal parts with large welding velocity and narrow weld cross section requires precise workpiece fit-up and accurate alignment of the beam with the joint line. The demands that these requirements put on welding fixtures, edge preparation methods and fit-up tolerances can act to dissuade potential users of laser welding technology, particularly if large components or fabrications, assembled from a number of smaller subcomponents, are to be welded. ${ }^{4}$

- Another consideration in selecting laser parameters for welding thick plates is the cooling rate. Because of the high speed and minimum heat input associated with the laser welding process, cooling rates are very high, leading to high hardness in steels with high carbon or high carbon equivalency. By selecting laser welding conditions that produce wider fusion zones and lower welding speeds, cooling time can be increased, resulting in less fusion zone hardness while still maintaining many of the advantages of laser welding. ${ }^{2}$
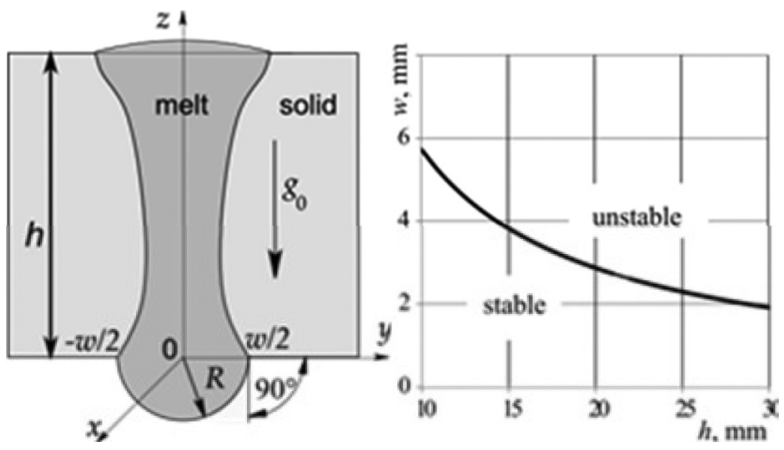

FIG. 2. (Left) maximum of the Laplace pressure, on the root surface of the weld pool. The contact angle is $90^{\circ}$, both the curvature radius $R$ and the sagging are equal to the half-width of the weld pool $w$. (Right) the stability threshold $w(h)$ for liquid steel, see Eq. (3b).

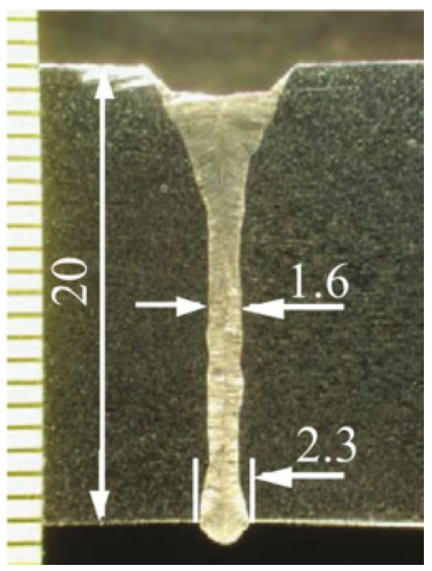

FIG. 3. Laser-arc hybrid weld of $20 \mathrm{~mm}$ thick AISI $316 \mathrm{~L}$ stainless steel with $18 \mathrm{~kW}$ laser power and $1.8 \mathrm{~m} \mathrm{~min}^{-1}$ welding velocity, see Ref. 3 .

- For many applications, filler material is required to compensate for joint fit-up or to change chemical composition in the weld metal. Extremely narrow weld pool cross section in combination with the short solidification time block an effective mixing of the filler material in the weld pool, see Ref. 3.

The idea to use oscillating [alternating current (AC)] magnetic fields for weld pool control to reduce sagging and to prevent gravity drop-out of the melt in high power laser beam welding of thick metal plates was developed in the frame of the International Thermonuclear Experimental Reactor (ITER) collaboration. ${ }^{5}$

Oscillating magnetic fields are widely used in metallurgical applications to control the melt dynamics in many industrial processes: crystal growth, casting, etc., see, e.g., Ref. 6. However, implementation of this technology in laser beam welding requires significant modification of the design of the AC magnet system. First welding tests with $8 \mathrm{~kW}$ (TRUMPF) disk laser (full penetration welding of up to $12 \mathrm{~mm}$ thick stainless steel plates) were performed at IFSW in Stuttgart. ${ }^{7}$

Welding tests with high-power lasers (20 kW IPG Ybfiber laser and $16 \mathrm{~kW}$ TRUMPF thin disk laser) were performed at BAM in Berlin, see recent review in Ref. 8. It was found that the AC power of $200 \mathrm{~W}$ at $450 \mathrm{~Hz}$ is enough for full compensation of the gravity forces in welding of $30 \mathrm{~mm}$ thick Al-alloy plates. ${ }^{9}$ For welding tests with $20 \mathrm{~mm}$ thick austenitic stainless steel in Ref. 10, the optimal value of the AC power was found to be $3 \mathrm{~kW}$ at $3 \mathrm{kHz}$, see Fig. 4 .

Computer simulations of the electromagnetic (EM) weld pool support process were performed at the BAM using the commercial finite element solver COMSOL MULTIPHYSics. ${ }^{10}$ The results of these simulations were used to optimize the parameters of the EM weld-pool support system. Note that austenitic stainless steel grades are nonferromagnetic.

The objective of the present study was to utilize the electromagnetic weld pool support technology in high power laser beam welding of ferromagnetic metals. Note that the Curie temperature for all ferromagnetic materials is lower than the melting temperature. However, the metal aside the heat affected zone remains ferromagnetic, see Fig. 5. 


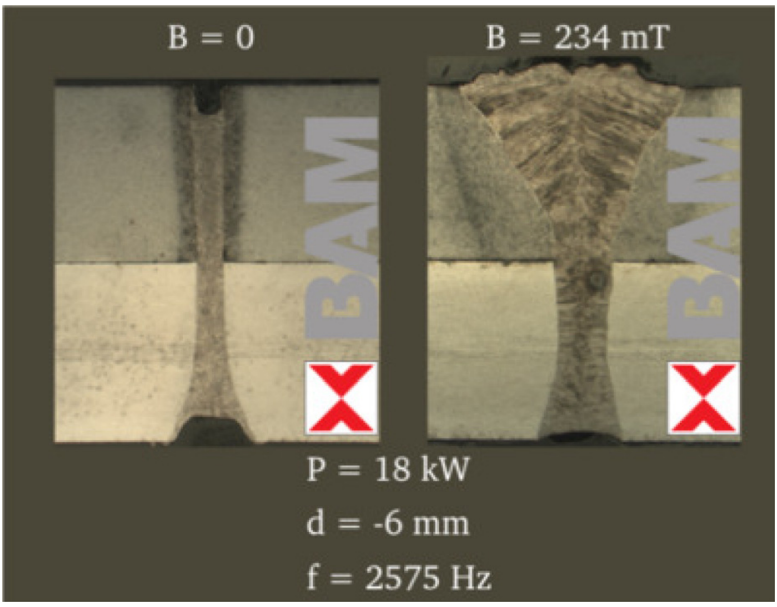

FIG. 4. PA position lap welding of lap welding of two $10 \mathrm{~mm}$ thick steel plates [S235JRC (up) and AISI 304 (bottom)] without and with the EM weld pool support, see Ref. 10. Laser beam power and welding speed were $18 \mathrm{~kW}$ and $0.5 \mathrm{~m} \mathrm{~min}^{-1}$, respectively.

Welding tests were performed on 15 and $20 \mathrm{~mm}$ thick plates of stainless duplex steel 2205 (1.4462). This alloy has a mixed two-phase microstructure of grains of (nonmagnetic) austenitic and ferritic steels, each having a content of about $50 \%$. The static magnetic permeability $\mu_{r}$ is much larger as 1 but much lower than that for mild steel grades, see Fig. 6 .

This fact allows the usage of a relatively simple model of ferromagnetic processes in the welded sample. The algorithms of computer simulation of the weld pool dynamics were modified to take into account ferromagnetic effects in the welded parts: nonlinear temperature-dependent magnetic permeability with hysteresis and saturation. ${ }^{12}$ The results of these calculations were used to optimize the parameter of the EM weld pool support process in high power laser beam welding of $15 \mathrm{~mm}$ thick duplex steel plates. Additional optimization of the design of the AC magnet was performed using a cold analog model - a plate of duplex steel with austenitic inclusion simulating the demagnetized region around the weld pool. The results of the welding tests confirm the results of computer simulations-the EM weld pool support also works in welding of ferromagnetic materials.

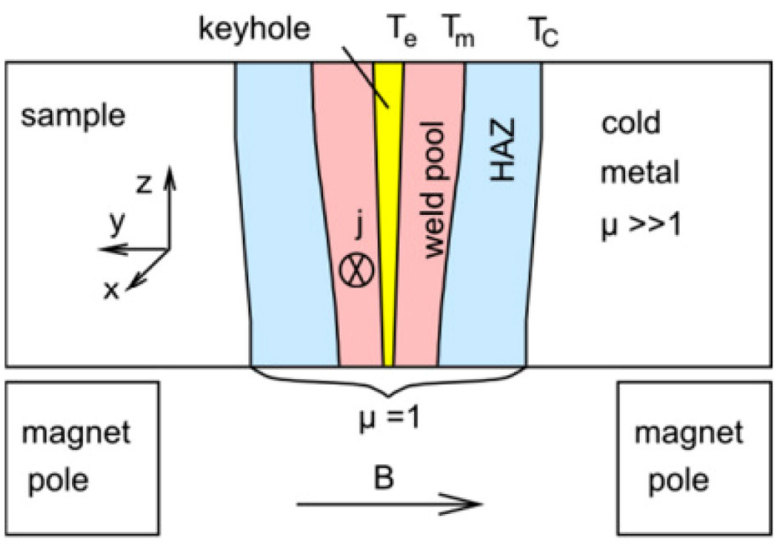

FIG. 5. Hot nonferromagnetic regions surrounded by ferromagnetic cold metal. $T_{e}, T_{m}$, and $T_{C}$ are isotherms relating to the evaporation, the melting, and the Curie temperatures, respectively.

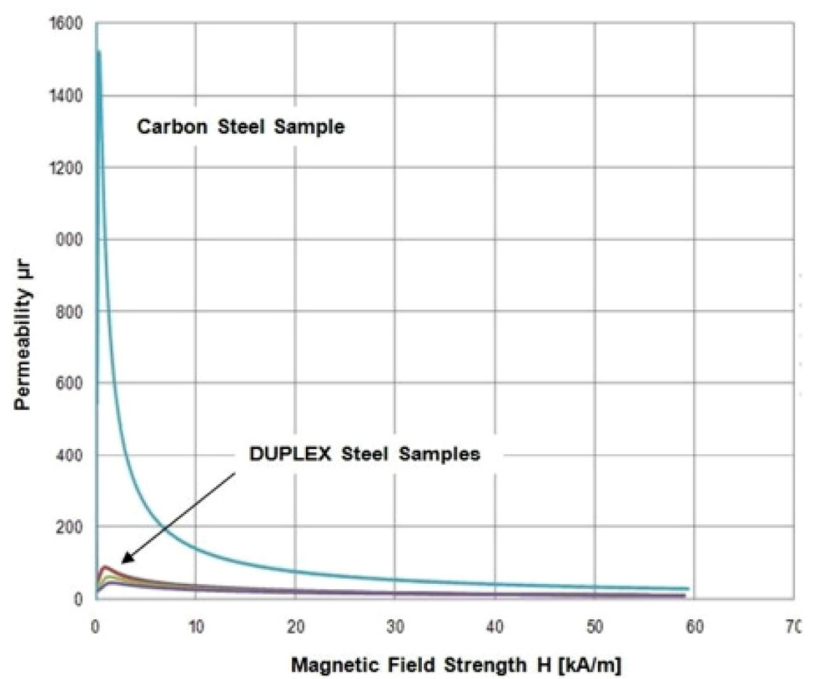

FIG. 6. Static magnetic permeability of duplex steel 2205 and carbon steel from Ref. 11.

The same EM weld pool support system was also successfully used in welding tests $20 \mathrm{~mm}$ thick plates. It was found that the $\mathrm{AC}$ power needed for a full compensation of the gravity is proportional to the plate thickness.

The next objective of the study was to compare the operation of the EM weld pool support system in combination with two high power solid state laser beam sources: $20 \mathrm{~kW}$ IPG Yb-fiber laser YLR-20000 and $16 \mathrm{~kW}$ TRUMPF Yb:YAG thin disk laser TruDisk 16002, see Table I. Naturally, welds performed with two different laser systems demonstrate different geometry of weld pool cross sections. However, the AC power needed for complete suppression of the root sagging was found to be independent of the welding speed. The only parameter determining the necessary value of $\mathrm{AC}$ power for a given value of the $\mathrm{AC}$ frequency is the thickness of the welded sample.

\section{PHYSICAL BACKGROUND}

The inductive EM weld pool support system utilizes eddy currents produced by an oscillating magnetic field generated by an AC magnet. Since the melt is nonferromagnetic $\left(\mu_{r} \approx 1\right)$, a simple analytical model based on the standard skin effect theory (see, e.g., Ref. 13) can be used to obtain a qualitative description of electromagnetic processes in the melt. The skin depth $\delta$ (the penetration depth for the AC magnetic field) is

TABLE I. Parameters of two laser and optical systems used in welding tests.

\begin{tabular}{lcc}
\hline \hline Laser beam source & $\begin{array}{c}\text { YLR-20000, } \\
\text { IPG photonics }\end{array}$ & $\begin{array}{c}\text { TruDisk 16002 } \\
\text { TRUMPF }\end{array}$ \\
\hline Max. beam power $(\mathrm{kW})$ & 20 & 16 \\
Wave length $(\mathrm{nm})$ & 1070 & 1030 \\
BPP $(\mathrm{mm} \times \mathrm{mrad})$ & 11.5 & 8 \\
Focal length $(\mathrm{mm})$ & 350 & 250 \\
Laser spot $(\mu \mathrm{m})$ & 560 & 500 \\
\hline \hline
\end{tabular}




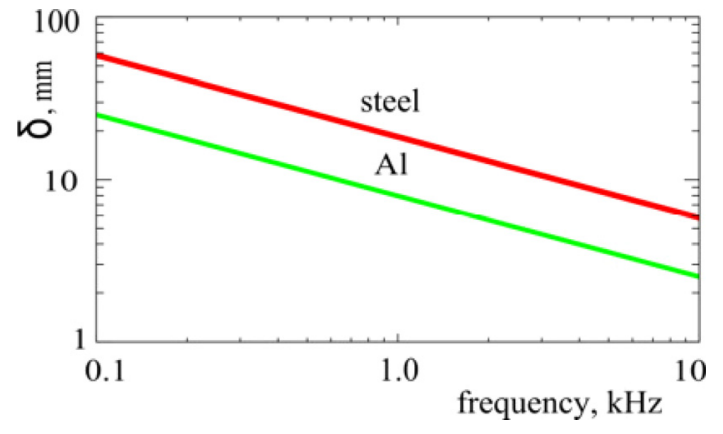

FIG. 7. Skin depth $\delta$ as a function of the AC frequency $f$ for liquid steel $\left(\sigma \approx 0.75 \times 10^{6} \mathrm{Si} \mathrm{m}^{-1}\right)$ and aluminum $\left(\sigma=4 \times 10^{6} \mathrm{Si} \mathrm{m}^{-1}\right)$.

$$
\delta=\left(\pi \mu_{0} \sigma f\right)^{-1 / 2}
$$

where $f$ is the frequency, $\sigma$ is the electrical conductivity of the melt, and $\mu_{0}=1.256 \times 10^{-6} \mathrm{H} \mathrm{m}^{-1}$, see Fig. 7 .

Two magnet poles are located left and right aside the weld pool, see Fig. 8. The magnetic field $\boldsymbol{B}$ is directed perpendicularly to the welding direction, whereas the electric current density $\boldsymbol{j}$ is directed parallel to it. The resulting Lorentz force $\boldsymbol{F}_{\mathrm{L}}=\boldsymbol{j} \times \boldsymbol{B}$ is directed along the $z$-axis and is able to support the weld pool. Its averaged over time value is

$$
\left\langle F_{L}(z)\right\rangle=\frac{B_{0}^{2}}{\mu_{0} \delta} \exp \left(-\frac{2 z}{\delta}\right),
$$

where $B_{0}$ is the rms-value of the applied magnetic field. This force can be also expressed as a gradient of the EM pressure

$$
p_{E M}(Z)=p_{m} \exp (-2 z / \delta)
$$

where $p_{m}$ is the EM pressure on the root surface of the sample

$$
p_{M}=B_{0}^{2} /\left(2 \mu_{0}\right)
$$

The EM pressure can partially (or fully) compensate the hydrostatic pressure, i.e., it is necessary to replace the

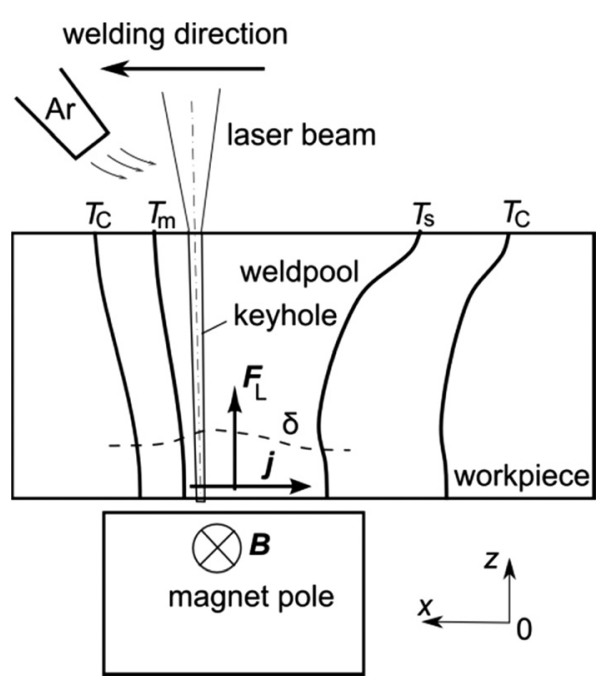

FIG. 8. Scheme of the EM weld pool support in full penetration PA position welding.

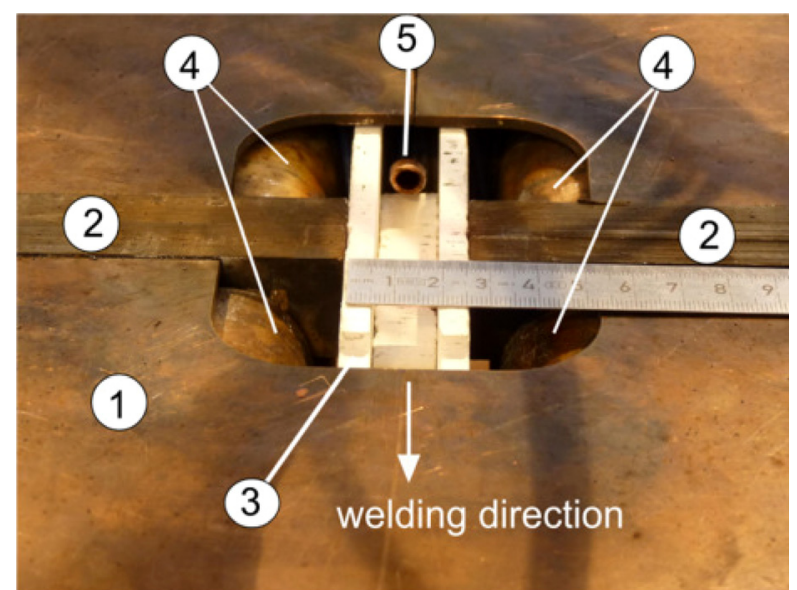

FIG. 9. AC magnet system used in welding tests: 1 -cover plate, 2-magnet poles, 3-ceramic protection of poles and coils, 4-magnet coils, 5-shielding gas nozzle on the root side (was not used in all welding tests).

hydrostatic pressure $p_{\mathrm{h}}$ in Eq. (3) with the difference $\left(p_{h}-p_{m}\right)$. The aim of the welding experiments was to find conditions for an ideal compensation: $p_{h}=p_{m}$. From the practical point of view, the most important parameter of the EM weld pool support is the AC power $P_{\mathrm{AC}}$ needed for ideal compensation. For nonferromagnetic metals $P_{\mathrm{AC}}$ is simply proportional to the EM-pressure. But in welding of ferromagnetic steel grades, the relation between $p_{m}$ and $P_{\mathrm{AC}}$ is nonlinear and can be found using experimental data for the concavity/convexity of the root seem as a function of the AC power supply.

\section{EXPERIMENTAL SETUP}

All welds were produced by traversing the sample relative to the laser optic head and the AC magnet, which were mounted stationary.

All welding experiments (full penetration bead-on-plate welding) were performed in PA position, see Fig. 8. The distance between the magnet poles and the sample was $2 \mathrm{~mm}$. The cross section of magnet poles was $25 \times 25 \mathrm{~mm}^{2}$, with $25 \mathrm{~mm}$ gap between the poles, see Fig. 9. The shielding gas

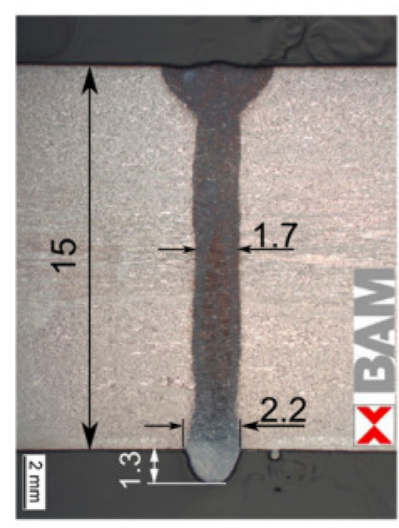

A3-1

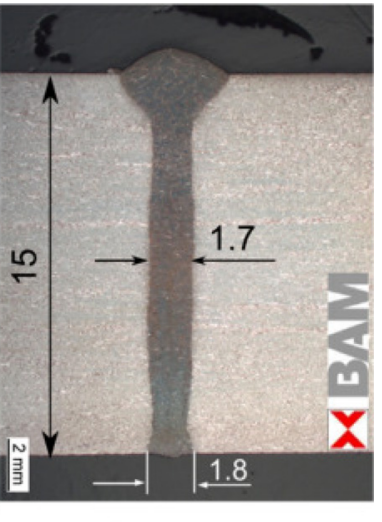

A2-3
FIG. 10. Cross sections of two welds performed with $1.0 \mathrm{~m} \mathrm{~min}^{-1}$ welding velocity without (left) and with (right) the EM weld pool support, see process parameters in Table II. 


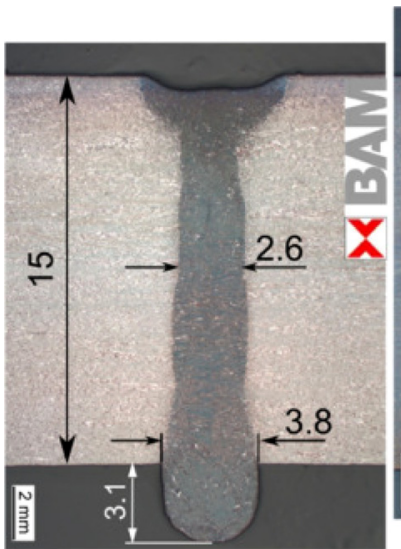

A5-1

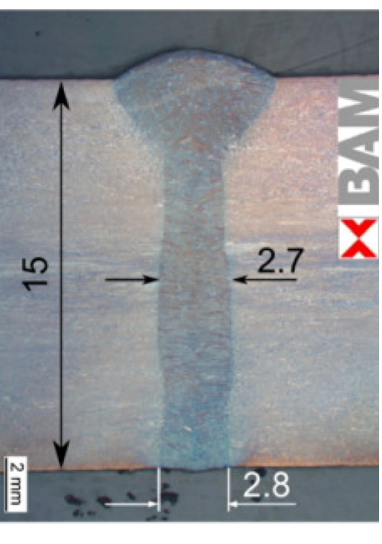

A7-2
FIG. 11. Cross sections of two welds plate performed with $0.5 \mathrm{~m} \mathrm{~min}^{-1}$ welding velocity without (left) and with (right) weld pool support, see Table II.

(industrial grade argon, $261 \mathrm{~min}^{-1}$ ) was supplied only to the front side of the weld pool.

\section{RESULTS AND DISCUSSION}

\section{A. Welding of $15 \mathrm{~mm}$ thick plates}

The first series of welding tests were performed with the IPG fiber laser, see Table I. The focal position was $z=-4 \mathrm{~mm}$.

Both welds shown in Fig. 10 were performed using $10.9 \mathrm{~kW}$ laser beam (IPG), the welding velocity was $1.0 \mathrm{~m}$ $\min ^{-1}$. The reference (without weld pool support) weld A3-1 demonstrates $\sim 2.2 \mathrm{~mm}$ weld width on the root side with $\sim 1.3 \mathrm{~mm}$ sagging. The surface tension can prevent the gravity drop-out and the melt remains stable, in accordance with the stability criterion in Eq. (3), see Fig. 2. However, the sag is too large and additional mechanical treatment would be needed to improve the quality on the root side.

The EM weld pool system can completely eliminate this sagging. The concavity/convexity oscillations on the root side of the weld A2-3 are smaller than $0.5 \mathrm{~mm}$. The AC power supply of $1.55 \mathrm{~kW}$ is much smaller than the laser beam power and does not influence the width of the weld.

For many applications, the weld width of $1.7 \mathrm{~mm}$ is too narrow. We have already discussed the possibility to use the EM weld pool support to reduce the welding speed to increase the weld width.

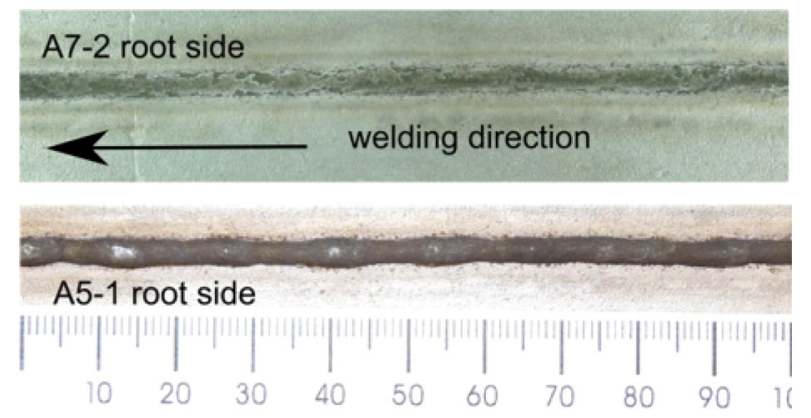

FIG. 12. Root side of two weld performed without (A5-1) and with weld pool support (A7-2).
TABLE II. Process parameters for welding of $15 \mathrm{~mm}$ thick plates with the IPG laser.

\begin{tabular}{lcccc}
\hline \hline Weld \# & A3-1 & A2-3 & A5-1 & A7-2 \\
\hline Laser power $(\mathrm{kW})$ & 10.9 & 10.9 & 8.56 & 8.56 \\
Welding speed $\left(\mathrm{m} \mathrm{min}^{-1}\right)$ & 1.0 & 1.0 & 0.5 & 0.5 \\
AC frequency $(\mathrm{kHz})$ & 0 & 2.4 & 0 & 1.18 \\
AC power $(\mathrm{kW})$ & 0 & 1.55 & 0 & 1.57 \\
\hline \hline
\end{tabular}

TABLE III. Process parameters for welding of $15 \mathrm{~mm}$ thick plates with TRUMPF laser.

\begin{tabular}{lcccc}
\hline \hline Weld \# & F3-4 & F3-2 & F2-3 & F1-1 \\
\hline AC frequency (kHz) & 0 & 1.21 & 1.77 & 2.5 \\
AC power (kW) & 0 & 1.41 & 1.59 & 1.98 \\
\hline \hline
\end{tabular}

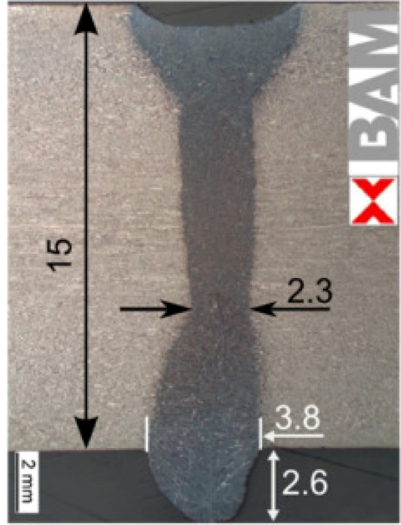

F3-4

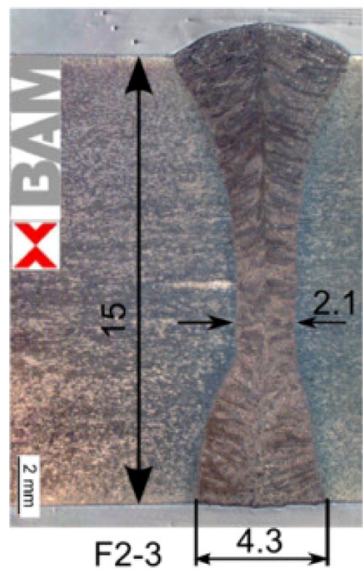

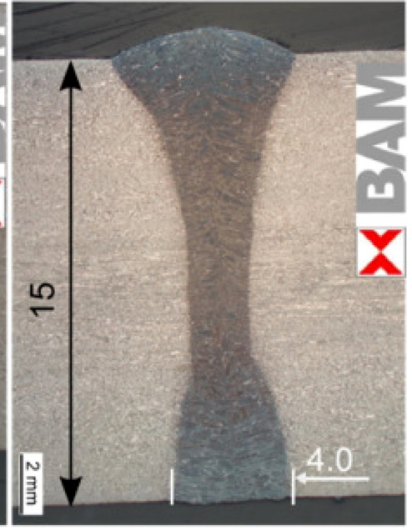

F3-2

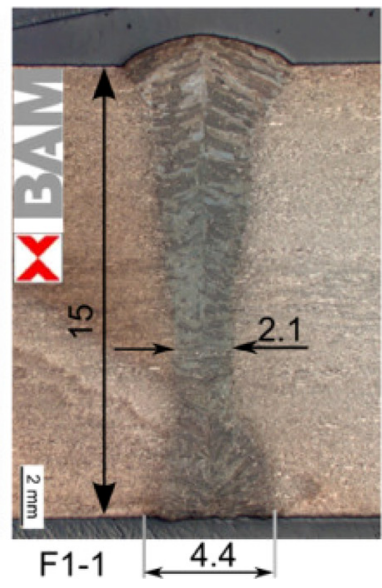

FIG. 13. Cross sections of four welds performed using the TRUMPF laser without and with weld pool support, see process parameters in Table III.
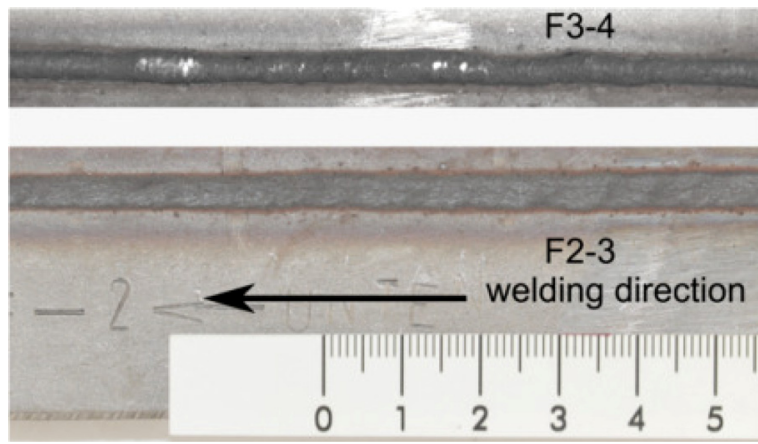

FIG. 14. Root side of welds F3-4 and F2-3. 
TABLE IV. Parameters of the EM weld pool support in $13.9 \mathrm{~kW}$ (TRUMPF) laser beam welding of $20 \mathrm{~mm}$ thick plates.

\begin{tabular}{lccc}
\hline \hline Weld \# & D2-3 & D3-1 & D4-2 \\
\hline AC frequency $(\mathrm{kHz})$ & 0.665 & 1.79 & 2.53 \\
AC power $(\mathrm{kW})$ & 2.03 & 1.86 & 2.15 \\
\hline
\end{tabular}

Additionally, it reduces also the laser beam power needed to reach a full penetration. Both welds shown in Fig. 11 were performed with $8.56 \mathrm{~kW}$ laser beam power; the welding velocity was $0.5 \mathrm{~m} \mathrm{~min}^{-1}$. Weld A5-1 was performed without weld pool support and demonstrates $3.8 \mathrm{~mm}$ weld width on the root side and $\sim 3.1 \mathrm{~mm}$ sag. These values are close to the instability region on Fig. 2.

Weld A7-2 was performed with $1.57 \mathrm{~kW}$ weld pool support and demonstrates almost constant seam width of $\sim 2.7 \mathrm{~mm}$ from the front to the root side of the sample.

Figure 12 shows photos of the root side for both welds performed with $0.5 \mathrm{~m} \mathrm{~min}^{-1}$. The reference weld A5-1 demonstrates large irregular saging. The weld width of the root side of weld A7-2 performed with EM weld pool support remains stable.

Note that the AC power needed to compensate the gravity is practically independent of the geometry of the weld cross section, the laser beam power, and the welding velocity.

The same EM weld pool system was used in welding tests with the TRUMPF thin disk laser $(8.6 \mathrm{~kW}$ beam power). The welding velocity was $0.5 \mathrm{~m} \mathrm{~min}^{-1}$, the focal position $z=-4 \mathrm{~mm}$. The process parameters of the EM weld pool support are summarized in Table III.

Figure 13 shows cross sections of four welds listed in Table III. Naturally, weld cross sections obtained in welding test with different lasers and optical systems are also different. In particular, the weld width on the root side is larger as that observed in welding tests with the IPG laser. Nevertheless, the EM weld pool support works perfectly. The optimal value of the AC power needed for full compensation of the gravity slightly increases with increasing frequency.

Figure 14 shows irregular root surface of the reference weld F3-4. The seam oscillates left and right; the sagging is also irregular. The EM weld pool support (weld F2-3) completely eliminates the sagging and stabilized the root surface of the seam.

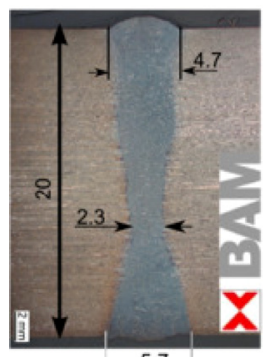

$\mathrm{D} 2-3+5.7 \rightarrow$

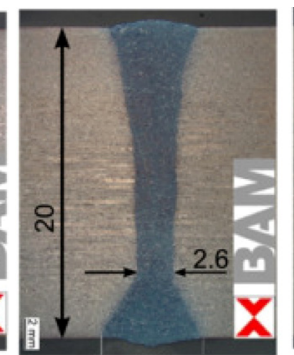

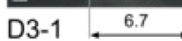

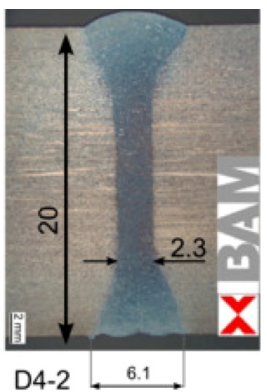

FIG. 15. Cross sections of three welds listed in Table IV.

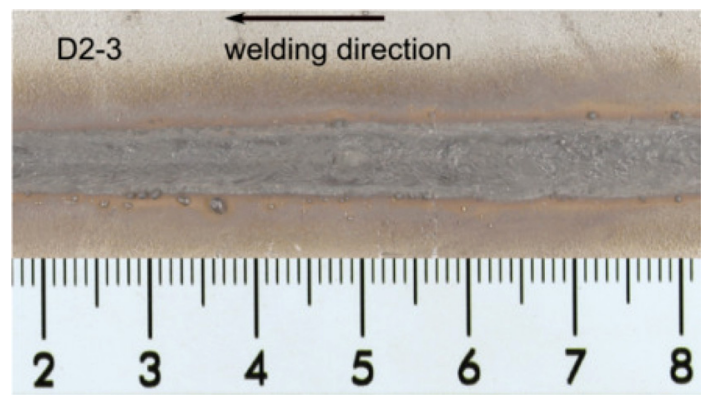

FIG. 16. Root side of weld D2-3.

\section{B. Welding of $20 \mathrm{~mm}$ thick plates}

Welding tests with $20 \mathrm{~mm}$ duplex steel were performed using the TRUMPF laser. The laser beam power and the welding velocity were fixed at $13.9 \mathrm{~kW}$ and $0.5 \mathrm{~m} \mathrm{~min}^{-1}$, respectively. The focal position was $z=-6 \mathrm{~mm}$. For this welding velocity full penetration welding of $20 \mathrm{~mm}$ thick steel plates without weld pool support is not possible, see Fig. 1. Parameters of the EM weld pool support needed to compensate the gravity are summarized in Table IV.

Figure 15 shows cross sections of three welds listed in Table IV. The weld width on the root side is larger than $\sim 6 \mathrm{~mm}$, but the EM weld pool support works perfectly. The optimal value of the AC power needed for full compensation of the gravitational forces is $\sim 2 \mathrm{~kW}$ or $100 \mathrm{~W}$ per mm of the plate thickness $h$. Note that the same value of the AC power per plate thickness was also observed in welding test with $15 \mathrm{~mm}$ duplex plates, i.e., the AC power needed for full compensation of the hydrostatic pressure is proportional to the plate thickness.

Figure 16 shows the root surface of the reference weld D2-3. EM weld pool support completely eliminates the sagging and stabilized the root surface of the seam.

\section{CONCLUSIONS AND OUTLOOK}

- The results of bead-on-plate full penetration high-power laser beam welding of up to $20 \mathrm{~mm}$ thick duplex steel 2205 plates in PA position were presented. An inductive contactless electromagnetic weld pool support system was successfully used to prevent gravity drop-out of the melt.

- For $15 \mathrm{~mm}$ thick plates full penetration was observed to occur at $10.9 \mathrm{~kW}$ or $8.56 \mathrm{~kW}$ laser power (YLR 20000, IPG) for 1.0 or $0.5 \mathrm{~m} \mathrm{~min}^{-1}$ welding speed, respectively. The electromagnetic weld pool support system operating at 2.4 or $1.18 \mathrm{kHz}$ needs about $1.6 \mathrm{~kW}$ AC power to completely compensate the weld sagging.

- Welding tests with $20 \mathrm{~mm}$ thick plates were performed with a TRUMPF Yb:YAG thin disk laser TruDisk 16002. Full penetration was observed to occur at $13.9 \mathrm{~kW}$ laser beam power and $0.5 \mathrm{~m} \mathrm{~min}^{-1}$ welding speed. The electromagnetic weld pool support system operating at $665 \mathrm{~Hz}$ needs about $2.03 \mathrm{~kW}$ AC power to prevent the gravity drop-out of the melt and completely compensate the weld sagging. 
- The results of welding tests show that the inductive weld pool support can be used in full penetration welding of thick plates of ferromagnetic steel grades.

- The results of the welding experiments performed with EM weld pool support offer perspectives for the proposed technology. In particular, this technology allows deep penetration laser beam welding in PE (overhead) position.

- The magnet must be located downside the welded sample. The penetration depth for AC magnetic fields $\delta$ must be smaller than the plate thickness, i.e., the upper side of the sample is free from AC magnetic fields. It means that the EM weld pool support can also be used in hybrid laser-arc welding.

\section{ACKNOWLEDGMENT}

Financial funding of the DFG (Bonn, Germany) under Grant No. DFG GU 1211/2-2 was gratefully acknowledged.

${ }^{1}$ LIA Handbook of Laser Materials Processing, edited by J. F. Ready and D. F. Farson (Laser Institute of America, 2001), p. 715.

${ }^{2}$ D. Farson and R. F. Duhamel, "Taking advantage of laser welding," Fabricator 28 (1998), available at http://www.thefabricator.com/article/ automationrobotics/taking-advantage-of-laser-welding.

${ }^{3}$ M. Karhu, V. Kujanpää, A. Gumenyuk, and M. Lammers, "Study of filler metal mixing and its implication on weld homogeneity of laser-hybrid and laser cold-wire welded thick austenitic stainless steel joints," in Proceedings of the ICALEO 2013 Congress, Miami, FL, 2013.

${ }^{4}$ C. M. Allen, P. A. Hilton, and J. Blackburn, "Increasing the tolerance to fit-up gap using hybrid laser-arc welding and adaptive control of welding parameters," in Proceedings of the 37th International MATADOR Conference, Manchester, England, 2012.

${ }^{5}$ L. P. Jones, P. Aubert, V. Avilov, F. Coste, W. Daenner, T. Jokinen, K. R. Nightingale, and M. Wykes, "Towards advanced welding methods for the ITER vacuum vessel sectors," Fusion Eng. Des. 69, 215-220 (2003).

${ }^{6}$ R. Moreau, Magnetohydrodynamics (Kluwer, 1990), p. 313.

${ }^{7}$ V. V. Avilov, R. Moldovan, P. Berger, Th. Graf, and D. Mock, "Electromagnetic weld pool control by $\mathrm{CO}_{2}$ and YAG disk laser welding of thick stainless steel plates," in Proceedings of the 6th International Conference on Electromagnetic Processing of Materials (EPM), Dresden, Germany, 2009.

${ }^{8}$ M. Bachmann, V. Avilov, A. Gumenyuk, and M. Rethmeier, "Experimental and numerical investigation of an electromagnetic weld pool control for laser beam welding," Phys. Procedia 56, 515-524 (2014).

${ }^{9}$ V. Avilov, A. Gumenyuk, M. Lammers, and M. Rethmeier, "PA position full penetration high-power laser beam welding of up to $30 \mathrm{~mm}$ thick $\mathrm{AlMg}_{3}$ plates using an electromagnetic weld pool support," Sci. Technol. Weld. Joining 17, 128-133 (2012).

${ }^{10}$ M. Bachmann, V. Avilov, A. Gumenyuk, and M. Rethmeier, "Experimental and numerical investigation of an electromagnetic weld pool support system for high power laser beam welding of austenitic stainless steel," J. Mater. Process. Technol. 214, 578-591 (2014).

${ }^{11} \mathrm{~W}$. Thale and H. Aue, "In-line metal loss inspection investigation of duplex pipeline," Proceedings of the 5th Pipeline Technology Conference, Hannover, Germany, 2010.
${ }^{12}$ M. Bachmann, R. Kunze, V. Avilov, and M. Rethmeier, "Finite element modelling of the AC electromagnetic weld pool support in full penetration laser beam welding of thick duplex stainless steel plates," in Proceedings of the ICALEO 2015 Congress, Atlanta, GA, 2015.

${ }^{13}$ L. D. Landau and E. M. Lifshitz, Electrodynamics of Continuous Media, Course of Theoretical Physics, Vol. 8 (Oxford, Pergamon, 1984).

\section{Meet the Authors}

Dr. rer. nat. Vjaceslav Avilov is with the Institute of Machine Tools and Factory Management at the Technical University Berlin. Before, he was with the BAM Federal Institute for Materials Research and Testing. His current activities include experimental work on electromagneticassisted high power laser beam as well as electron beam welding processes.

B. Sc. André Fritzsche, born in 1987, is a master student in Mechanical Engineering at the TU Berlin. The topic of his master work is an optimization and experimental verification of the electromagnetic weld-pool control system in highpower $(\sim 20 \mathrm{~kW})$ laser beam welding of thick plates of ferromagnetic metals. Since 2011 he has been also a member of Professor Rethmeier's department "Welding Technology" at the BAM.

Dr.-Ing. Marcel Bachmann, born 1984 in Berlin, is with the BAM Federal Institute for Materials Research and Testing in Berlin, Germany in the department "Welding Technology" since 2009. He received his diploma from the Technical University Berlin in Physical Engineering and his $\mathrm{Ph} . \mathrm{D}$. for numerical investigations of electromagnetically assisted high power laser beam welding processes. Currently, he is working on several projects involving numerical simulations in welding processes.

Dr.-Ing. Andrey Gumenyuk is the head of the working group "Laser beam welding processes" at the BAM Federal Institute for Materials Research and Testing in Berlin, Germany in the department "Welding Technology." He received his Ph.D. from the technical university (RWTH) Aachen in Mechanical Engineering. The focus of his work is high-power laser and laser-arc hybrid welding technologies.

Univ.-Professor Dr.-Ing. Michael Rethmeier studied Mechanical Engineering at the Brunswick University of Technology in Brunswick/Germany. Since 2007, he has been a Professor in the "Safety of Joined Components" Faculty at the Technical University Berlin and the Head of division "Joining Technology" at Federal Institute for Materials Research and Testing (BAM), Berlin. Since 2009, he has also been the Manager of the Joining and Coating Technology Division at the Fraunhofer Institute for Production Installations and Design Engineering, Berlin. 